\title{
Development of natural acne patch from local materials using quality function deployment technique
}

\author{
Nattawadee Kapao and Wassanai Wattanutchariya* \\ Advanced Manufacturing Technology Research Center (AMTech), Department of Industrial Engineering, Faculty of Engineering, \\ Chiang Mai University, Chiang Mai 50200, Thailand.
}

\begin{abstract}
This research aims to develop an acne patch based on local material extracted from silk and mulberry and the implementation of quality tools. The development started with a consumer needs' survey about the acne patch product. Technical requirements were evaluated based on quality function deployment (QFD) technique phase 1 or house of quality (HoQ). The results show that the highest score of consumer requirements is standard, followed by acne pus absorption and acne bacteria inhibition property, respectively. After transforming the consumer requirements into technical requirements, it was found that the highest score of technical requirements is qualified to anti-acne bacteria test, followed by swelling and antioxidant property, respectively. According to QFD result, the product prototype was developed using local materials extract and then evaluated based on consumer satisfaction. The most consumer satisfying feature of the natural acne patch product was the acne treatment and no irritation properties. However, the consumer made suggestion on the strength and stickiness of the product for further improvement.
\end{abstract}

\section{Introduction}

The cosmetic industry is one industry that is growing and expanding continuously. Cosmeceuticals are another option for people who care for themselves, whether male and female consumers. Cosmeceuticals combines the properties of cosmetics and drugs together. [1] It is a new product category in cosmetic industry. According to statistics, the market for cosmeceutical in Thailand has a market value of up to 2,000 million baht per year and a high growth rate of 30 percent per year, making the cosmeceutical product sector grow rapidly. Most cosmeceuticals are skin care and skin repair product. For example, they help increase radiance, add moisture, eliminate dullness and reduce wrinkles. They are also used to relieve the acne problem. [1-3] Acne treatment is available in many forms, such as drugs, comedone extractor and Intralesional Kenacort. Acne patches are another method to treat acne. It can conceal and treat acne at the same time. Acne patches are popular among consumers because it is portable and easy to buy. Generally, acne patches in the market are composed of

hydrocolloid a synthetic substance. If there is a natural acne patch product, then there are no synthetic substances. It may be another option for consumers who are interested in natural products. However, those natural products need to have properties that meet the requirement for cosmeceutical. Silk and mulberry are local materials that can be easily produced or grew in Thailand. [4] Silk consists of fibroin and sericin. Fibroin can enhance the growth rate of fibroblast which can quickly treat acne wounds. [5] Meanwhile, mulberry extract has substances which can inhibit and kill acne bacteria. [6] Furthermore, fibroin and mulberry extract have antioxidant properties. $[7,8]$ Because of the range of cosmeceutical products in market, consumers are able to choose products that can satisfy their needs. Therefore, manufacturer must make their product to be interesting and be able to response to consumer's expectation. Thus, the purpose of this research is to develop an acne patch made from silk extract and mulberry extract. Principle of product design and development tools along with the house of quality

\footnotetext{
* Corresponding author: wassanai@eng.cmu.ac.th
} 
technique were employed as tools to develop the acne patches from local materials, as well as to satisfy the consumer's needs and be able to compete in the cosmeceutical market.

\section{Materials and methods}

The research methodology started with preparing the fibroin extract, mulberry extract and chitosan. Then, the QFD was employed to develop the acne patch prototype, which then was evaluated based on consumers satisfaction.

\subsection{Local material preparation}

\subsubsection{Silk Extract preparation}

Silk cocoons were cleaned and cut into small pieces. Then, the pieces were boiled in solution of $0.02 \mathrm{~mol} \mathrm{Na}_{2} \mathrm{CO}_{3}$ for 30 minutes. After that, the solution was washed with distilled water for 10 minutes. The extraction procedure was repeated two times before drying in hot air oven at $37^{\circ} \mathrm{C}$ for 12 hours. Next, the degummed silk was dissolved in 3 solutions of $\mathrm{CaCl}_{2}: \mathrm{CH}_{3} \mathrm{CH}_{2} \mathrm{OH}$ : DI water at $70^{\circ} \mathrm{C}$, followed by soaking the extracts packed in a cellulose membrane in distilled water for 3 days. Next, they were centrifuged at $2000 \mathrm{rpm}$. for 10 minutes and stored at $20^{\circ} \mathrm{C}$ and $-80^{\circ} \mathrm{C}$ for further processing by lyophilization. $[7,9]$

\subsubsection{Mulberry Extract preparation}

Mulberry leaf was cleaned before extraction with water at $45^{\circ} \mathrm{C}$ for 3 hours. The extracts were spin by centrifuge, with the supernatant liquid collected and filtered by filter paper. Then, rotary evaporation under reduced pressure at $45^{\circ} \mathrm{C}$ for sublimation was performed until the water was removed. [8]

\subsubsection{Chitosan preparation}

Commercial chitosan that produced by squid pen was purchased from a local supplier. Chitosan was prepared in lactic acid for 3 days. Then, it was stirred until homogeneous before adding into the mixture. $[5,9]$

\subsection{Consumer needs evaluation}

Total of 20 consumers who had used acne patch before, were recruited and interviewed in order to develop the questionnaire for QFD implementation. After gathering raw data from the interview answers, it was converted to consumer needs. Then, consumer needs were categorized by tree diagram for easy conversion to the features of acne patches and state on the questionnaire. Then, this questionnaire was distributed online to target consumer which the related question focused on the voice of customer towards acne patch products in the market, criteria in buying decisions and product satisfaction.

\subsection{QFD matrix development}

Data from online questionnaires were applied in a HOQ matrix. HOQ was thus created from finding the relationship between consumer requirements and technical requirements. Including to, itself relationship of technical requirements and define target values of technical requirements.

\subsection{Prototype development}

The technical requirements that have a high score of at least 2 from HOQ was chosen to develop a product prototype before analyzing and assessment.

\subsection{Consumer satisfaction assessment}

The prototype was assessed by 20 assessors using a sensory evaluation and questionnaire by focus group. The result was analyzed and can tell how much the consumers are satisfied with the acne patch product that was developed.

\section{Results and discussion}

\subsection{Local material characterization}

The local material was tested for cytotoxicity by MTT reduction assay, which found that all of extraction and preparation of substrate were not toxic to cells. Silk extract was verified by Fourier transforms infrared spectroscopy (FTIR), which confirmed the standard property of general silk extraction.

\subsection{Evaluation of consumer's response}

The result from consumers responses show that the general acne patch can fix the acne problem by absorbing pus in the acne and concealing acne. But they cannot treat acne or kill the acne bacteria, so this acne patch should treat and fix the acne problem at the same time. Moreover, if the acne patch contains natural ingredients it can enhance the consumer satisfaction. By analyzing and summarizing the consumers' needs, a tree diagram was employed to show the consumer's needs in to proper category, as shown in figure 1. The importance rating of consumers' needs is presented on the left side of the HoQ. The result of consumer survey on acne patch development is also shown in figure 2. This score showed that the priority of consumer's requirement is the product safety, with a score of 4.46. In second place is the ability to absorb acne pus, with a score of 4.39 , following by acne bacteria inhibition and good adherence to the face with score of 4.38 and 4.28 , respectively. In fact, most consumers are interested 


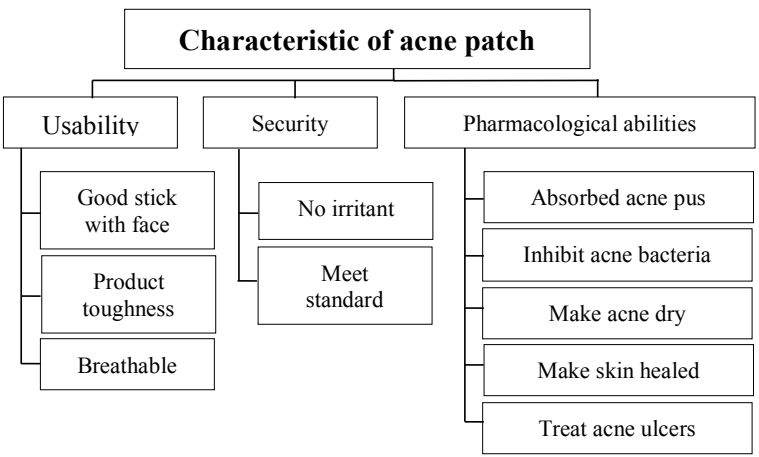

about acne patch made from natural, which is safer than synthetic substance and do not cause allergic reactions.

\subsection{Application of HoQ for acne patch}

HoQ is a tool to transform customer needs into product specification, which then is converted into product prototype which can be used to evaluate consumer satisfaction as well as to seek for further improvement.

Fig. 1. Tree diagram of consumer needs on acne patch

\begin{tabular}{|c|c|c|}
\hline Symbol & Meaning & Score \\
\hline & No relationship & 0 \\
\hline$\Delta$ & Possible & 1 \\
\hline O & Moderate relationship & 3 \\
\hline & Strong relationship & 9 \\
\hline
\end{tabular}

\begin{tabular}{|c|c|}
\hline Symbol & Meaning \\
\hline & No impact \\
\hline++ & Strong positive \\
\hline+ & Moderately positive \\
\hline- & Moderately negative \\
\hline-- & Strong negative \\
\hline
\end{tabular}

Movement of Target Value

\begin{tabular}{cc}
$\uparrow \quad$ Large the better \\
\hline $\mathrm{O}$ Target the best
\end{tabular}

O Target the best

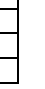

Demand factors that affect product attributes 
The goal of this technique is ensuring that the product can meet the consumer's expectation. $[10,11]$ In defining relationships, symbols were used to show the type of relationship between consumer requirements and technical requirements. The symbols replaced the scores were that calculated as relative technical scores. HoQ was used to find the most important technical requirements of the acne patch product that shown in figure 2. The technical requirements that should be developed in the acne patch product include proven to treat acne with a score of 109.1, efficacy of liquid suction and healing lesion from acne with a score 100.4 and 81.78 respectively. Therefore, all three are importance attribute in the development of acne patch prototype.

\subsection{Prototype of natural acne patch}

The prototype was fabricated based on local materials and lyophilization is shown in figure 3. An initial cost evaluation of the prototype natural acne patch product is $3.33 \mathrm{baht} / \mathrm{piece}$.
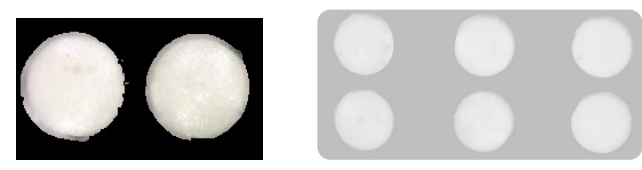

Fig. 3. Prototype of natural acne patch

\subsection{Evaluation of consumer satisfaction}

Focus group technique was employ for consumer's satisfaction evaluation. The result shows that most consumers had good level of satisfaction with the product's prototype. The consumers satisfied with the safety of the natural product. Moreover, it can treat the acne problem. Cost is another mentioned factor, which is found to be in an acceptable range. However, customers showed concern about the solidity of the patch's structure, as well as the stickiness of the product.

\section{Conclusion}

Three types of local material: silk extract, mulberry extract and chitosan were synthesized and fabricated into a natural acne patch product. These materials have been assessed to do no harm to cells in preliminary test and pass the property for acne treatment. Quality function deployment was implemented to evaluate the consumer needs and found that the important requirement is meeting the safety standard, followed by absorbance of acne pus and inhibition of acne bacteria, respectively. After transforming into technical requirements, it was found that the first important technical requirements is the efficiency of acne treatment, followed by efficacy of liquid suction and healing lesion from acne, respectively. Therefore, these specifications were than used to help develop a prototype. Afterward, this prototype was evaluated for consumer satisfaction, which found to be in good agreement with HoQ result. The main criteria of satisfaction are safety as it is the natural product, followed by acne treatment, color, smell, and cost of product. The recommendations for further improvement are strength and stickiness of the product.

\section{Acknowledgement}

The authors appreciate the financial support from the Graduate School of Chiang Mai University.

\section{References}

1. Nanjwade, B.K., Development of Cosmeceuticals. World Journal of Pharmacy and Pharmaceutical Sciences, 2017: p. 643-691.

2. Manela-Azulay, M. and E. Bagatin, Cosmeceuticals vitamins. Clin Dermatol, 2009. 27(5): p. 469-74.

3. Gao, X.H., et al., Efficacy and safety of innovative cosmeceuticals. Clin Dermatol, 2008. 26(4): p. 367-74.

4. Vepari, C. and D.L. Kaplan, Silk as a Biomaterial. Prog Polym Sci, 2007. 32(8-9): p. 991-1007.

5. Zhang, X., et al., Silk fibroin microfibers and chitosan modified poly (glycerol sebacate) composite scaffolds for skin tissue engineering. Polymer Testing, 2017. 62: p. 88-95.

6. Emniyet, A.A., et al., Antioxidant and antimicrobial activities with GC/MS analysis of the Morus alba $L$. Leaves. Hittite Journal of Science \& Engineering, 2015. 1(1): p. 37-41.

7. Thunsiri, K., S. Udomsom, and W. Wattanutchariya, Characteristic of Pore Structure and Cells Growth on the Various Ratio of Silk Fibroin and Hydroxyapatite in Chitosan Base Scaffold. Key Engineering Materials, 2016. 675-676: p. 459-462.

8. Arabshahi-Delouee, S. and A. Urooj, Antioxidant properties of various solvent extracts of mulberry (Morus indica L.) leaves. Food Chemistry, 2007. 102(4): p. 1233-1240.

9. Sionkowska, A. and A. Płanecka, Preparation and characterization of silk fibroin/chitosan composite sponges for tissue engineering. Journal of Molecular Liquids, 2013. 178: p. 5-14.

10. Wattanutchariya, W. and P. Krutasood. Purple rice dessert product development by Quality Function Deployment technique and Mood Consumption concept. in Industrial Engineering and Engineering Management (IEEM), 2015.

11. Kasemset, C., N. Kumpong, and W. Wattanutchariya, Processed Parboiled-Rice Product Development Using HoQ Technique. Advanced Materials Research, 2014. 931-932: p. 1642-1646. 